\title{
Brincando e aprendendo: uma proposta lúdica de inclusão social e digital para pacientes de serviços de Oncologia Pediátrica
}

\author{
Juliana Maria Oliveira dos Santos ${ }^{1}$, Débora A. Santos ${ }^{1}$, Amanda S. de M. Gomes ${ }^{1}$ \\ ${ }^{1}$ Universidade Federal da Bahia (UFBA) - Instituto de Matemática e Estatística \\ Departamento de Ciência da Computação \\ Av. Adhemar de Barros, S/N, Ondina - CEP 40.170-110 - Salvador - BA - Brasil
}

\{joliveira, abdalla, asmg\}@dcc.ufba.br

\begin{abstract}
This paper presents the results of the use of online games in conjunction with the curriculum worked in hospital class, in order to create opportunities to improve the quality of life for children and adolescents with onco-haematological disease, which had their traditional education discontinued because of changes in their routines resulting from cancer treatment .

Resumo. Este artigo apresenta os desdobramentos da utilização de jogos online em articulação com os conteúdos escolares trabalhados na classe hospitalar, com vistas a oportunizar uma melhoria da qualidade de vida para crianças e adolescentes com doença onco-hematológica, os quais tiveram sua educação tradicional descontinuada por conta da alteração de suas rotinas como consequência do tratamento contra o câncer.
\end{abstract}

\section{Introdução}

A Constituição Federal Brasileira de 1988 (BRASIL, 1988) diz que a educação é direito de todos e dever do Estado e da família, visando ao pleno desenvolvimento da pessoa, seu preparo para o exercício da cidadania e sua qualificação para o trabalho. Carvalho \& Begnis (2006, p. 109) afirmam que, no contexto de unidades de internação hospitalar, crianças e adolescentes "são afastados de seu ambiente familiar, de seus amigos, da escola e de seus objetos pessoais, perdendo assim grande parte de suas referências", acarretando na diminuição no ritmo de desenvolvimento cognitivo e social destes.

Nessa conjuntura a inclusão do universo de crianças/adolescentes hospitalizados consolida-se por meio das legislações sobre as Classes Hospitalares, reconhecidas como "ambientes que propiciam a continuidade do processo educacional e fortalecem as ações com vistas à promoção da saúde das crianças e adolescentes em situação de internação" (BATISTA, 2014, p. 25). Aliadas a estas estão ainda as brinquedotecas, espaços obrigatórios em unidades de saúde que ofereçam atendimento pediátrico em regime de internação, de acordo com a Lei Federal no 11.104 (BRASIL, 2005). Para Santos (1997, p.13), "a brinquedoteca é um espaço que se caracteriza por possuir um conjunto de brinquedos, jogos e brincadeiras, sendo um ambiente agradável, alegre e colorido, onde mais importante que os brinquedos é a ludicidade que estes proporcionam". 
O caráter de integração e interação contidos nas atividades lúdicas contribuem e oportunizam aos indivíduos momentos de socialização, expressão, criação e de troca de informação, revelando também uma dimensão educativa ao tornar o processo de ensino/aprendizagem desafiador, motivador, descontraído e prazeroso, auxiliando na minimização do sentimento de isolamento e medo intrínseco ao contexto de hospitalização.

Nas palavras de Nigro (2004), doenças como o câncer constituem uma violência impositiva em razão da necessidade de tratamento e das várias internações. Segundo Ferrão (2007), "a partir do diagnóstico de câncer, abre-se o caminho de um tratamento incerto, doloroso, prolongado, que marca o corpo, choca a família, muitas vezes afasta os amigos, fragiliza os planos de futuro e torna iminente a possibilidade de morrer" (apud LIMA et al., 2012, p. 106). Observa-se, portanto, que para crianças e adolescentes, a doença traz grandes impactos na vida escolar e no desenvolvimento de competências metacognitivas e socioemocionais.

Apesar dessa realidade difícil, os indivíduos acometidos pelo câncer, em especial crianças e adolescentes, continuam a desenvolver-se, ter fantasias, emoções e sentimentos e, nesse sentido, o trabalho de Soares e Santarosa (2007, p. 432) aponta "a importância de se colocar à disposição de crianças hospitalizadas, instrumentos que possibilitem a interação virtual com outras pessoas, que oportunizem aprendizagens, que favoreçam o seu desenvolvimento". Portanto, faz-se necessária a prestação de uma assistência holística e de qualidade.

Soares e Santarosa (2007, p. 431) enfatizam que "considerando a necessidade humana de manter vínculos afetivos, o computador, dispositivo portátil e de fácil acesso pode, mesmo em isolamento, transpassar as barreiras impostas e ser uma ligação com a realidade de fora do hospital". Neste sentido, "a adoção das tecnologias digitais, incluindo a internet, no processo educativo de indivíduos hospitalizados, constitui-se em um instrumento que promove o desenvolvimento da autonomia no processo de aprendizagem, a inclusão digital e social, a expressão e comunicação de ideias e sentimentos" (SANTOS; SANTOS e GOMES, 2016) e, consequentemente, contribui para a elevação da autoestima destes sujeitos.

Este trabalho apresenta os desdobramentos da utilização de jogos online em articulação com os conteúdos trabalhados em uma classe hospitalar, com vistas a oportunizar uma melhoria da qualidade de vida para crianças e adolescentes com doença onco-hematológica, no aspecto de seu desenvolvimento no processo de inclusão social e digital. O trabalho realizado pelo programa permanente de extensão da Universidade Federal Bahia, o Programa Onda Digital, desenvolve-se nas instalações do Grupo de Apoio à Criança com Câncer - Bahia (GACC - Bahia).

Criado em 1988, o GACC, tem a missão de promover a assistência psicossocial, médica e financeira às crianças e adolescentes com câncer oriundas de famílias carentes do estado da Bahia. A instituição também promove a realização de atividades de cunho cultural e educativo, com diversos projetos que visam o incentivo à leitura e à escrita, na perspectiva de uma assistência integral e de qualidade.

Desde 2002, a instituição conta com uma brinquedoteca cujo espaço físico é composto de áreas destinadas a oficinas, atividades livres, leitura com uma mini 
biblioteca, palco e arquibancada formando um mini teatro, além de uma sala de informática com 6 (seis) computadores. A implantação da brinquedoteca da instituição surgiu como mais uma alternativa para auxiliar no tratamento, ampliando a assistência dentro do contexto de humanização.

O GACC atende um público diversificado, contemplando crianças e adolescentes de 0 a 19 anos, com diferentes níveis de escolaridade e concepções culturais, provenientes de diferentes cidades e com patologias diversas, acarretando na formação de classes hospitalares multisseriadas. Esta diversidade nos processos educativos requer o respeito às necessidades individuais, considerando as características sociais, emocionais e culturais das crianças e adolescentes hospitalizados, flexibilizando o processo de ensino/aprendizagem.

De acordo com Ortiz e Freitas (2001), falar em educação pensando na diversidade nos leva a práticas educativas em espaço considerado não convencional, por profissionais igualmente considerados não convencionais (apud BATISTA, 2014, p. 12). Assim, a prática pedagógica em ambientes hospitalares requer o envolvimento de outros saberes, além do pedagógico, e o desenvolvimento de estratégias que contemplem diversos perfis, possibilitando uma aprendizagem personalizada que promova aos educandos a construção de novos conhecimentos e atitudes.

O artigo está organizado da seguinte forma: A seção 2 apresenta os materiais e métodos utilizados. A seção 3 descreve a análise dos resultados. A seção 4 apresenta as conclusões do trabalho. A seção 5 os agradecimentos e por fim, as referências.

\section{Materiais e métodos utilizados}

Desde 2012 o Programa Onda Digital realiza oficinas de informática básica para as crianças, adolescentes e acompanhantes dos pacientes assistidos pelo Grupo de Apoio à Criança com Câncer - Bahia (GACC - BAHIA). O público-alvo é dividido em três subgrupos, a saber: a) crianças (dos 4 anos até os 9 anos), b) adolescentes (dos 10 anos até os 19 anos) e c) acompanhantes. Em virtude do perfil heterogêneo dos pacientes, alto índice de rotatividade e tempo de permanência na unidade hospitalar não definido e dependente da fase de tratamento na qual o paciente se encontra, as atividades propostas não podem ser sequenciais, devendo iniciar e terminar no mesmo encontro.

Atuam como oficineiros estudantes de graduação da Universidade Federal da Bahia, participantes do programa de extensão Onda Digital como bolsistas ou voluntários e estudantes do componente curricular, modalidade disciplina, denominado Ação Curricular em Comunidade e em Sociedade (ACCS). A ACCS: Onda Solidária de Inclusão Digital - Tecnologia a Serviço da Cidadania, possibilita aos estudantes de graduação a aproximação e interação com a comunidade promovendo a troca de conhecimentos sobre as Tecnologias Digitais de Informação e Comunicação (TDIC), especialmente no uso de softwares livres. São envolvidos estudantes de graduação de diversas áreas do conhecimento, proporcionando às oficinas abordagens interdisciplinares.

Para atuar no GACC como oficineiro nesta atividade de orientação em informática básica, recomendamos a presença de pelo menos três oficineiros para que 
cada um dê atenção a no máximo 2 pacientes. Além disso, destacamos como características fundamentais para desenvolver esta atividade, pessoas com uma boa estrutura emocional e psicológica, que demonstre afetividade e atenção no trabalho e com habilidade para elevar a autoestima das crianças e adolescentes hospitalizados.

Uma preferência entre as crianças e adolescentes que frequentam o GACC são os jogos online. Para melhorar a qualidade de vida destes pacientes, proporcionando a continuidade dos estudos dos mesmos, buscamos articular os jogos online com os conteúdos vistos na classe hospitalar, utilizando o lúdico para tornar o aprendizado mais divertido e prazeroso. As oficinas são planejadas, virtual ou presencialmente, pelos estudantes de graduação sob a supervisão de professores e monitores. As oficinas acontecem uma ou duas vezes por semana no GACC e tem duração de 40min (quarenta minutos) para cada subgrupo. O diário de campo da atividade é registrado no Ambiente Virtual de Aprendizagem (AVA) Moodle utilizando o recurso Fórum de Discussão. Durante os encontros semanais da ACCS os estudantes compartilham oralmente entre si os acontecimentos na execução das atividades. Nesta fase são avaliados coletivamente os efeitos da ação, destacando-se os pontos positivos e negativos das atividades propostas, buscando identificar os tipos de atividades que tiveram maior aderência e aperfeiçoar aquelas que não foram bem aceitas.

O estímulo do raciocínio lógico, o desenvolvimento da criatividade, da coordenação motora e do processo de construção do conhecimento, são trabalhados por meio da utilização de jogos online educacionais, facilitando, a associação do lúdico com os conteúdos escolares vistos nas classes hospitalares. Além disso, a escolha dos jogos leva em consideração outra série de cuidados e critérios, relacionados ao indivíduo e ao jogo em si. Em relação aos indivíduos, consideramos aspectos como: faixa etária, nível de familiaridade com o computador, se é portador de deficiência e suas preferências. No que tange ao jogo, consideramos o tipo do jogo, o conteúdo educacional abordado e se o mesmo possui boa jogabilidade, considerando aspectos como objetivos e regras bem definidos, pontuação, desafios e fases diversas.

Uma preocupação na seleção dos jogos diz respeito ao nível de alfabetização do indivíduo. O público-alvo da instituição é composto por indivíduos de diferentes idades e níveis de alfabetização. Neste quesito, Antunes (1999, p.17) destaca que:

\footnotetext{
Existem expressivas diferenças entre os jogos para crianças não alfabetizadas e crianças que se alfabetizam. Para as crianças não alfabetizadas ainda, os jogos devem ser vistos como leituras da realidade e como ferramenta de compreensão de relações entre elementos significativos (palavras, fotos, desenhos, cores, etc.) e seus significados (objetos).
}

Em relação a jogos violentos (denominamos assim os jogos em que algum personagem morre ou aqueles que possuem cenas com sangue), optou-se por eliminálos da seleção de jogos propostos, em virtude da divisão da comunidade científica quanto aos possíveis efeitos comportamentais causados por jogos do tipo, além de que tal temática reforçaria o conflito de vida e morte que já está severamente presente no cotidiano do público em questão.

Durante a escolha do jogo, os estudantes de graduação devem testá-lo jogando, buscando identificar os pontos positivos e negativos do mesmo, seus objetivos, regras, 
comandos e nível de dificuldade, com o objetivo de realizar uma orientação adequada às crianças e adolescentes. O planejamento das oficinas é construído colaborativamente e, durante esta fase, os links para acesso aos jogos propostos são disponibilizados para todos os membros da equipe. Cada estudante deve realizar testes e dar um feedback, apontando os pontos positivos e negativos dos jogos analisados.

No GACC são proporcionadas condições para a permanência em tempo integral de um dos pais ou responsáveis das crianças e adolescentes hospitalizados. Desta forma, os acompanhantes dos pacientes também participam das atividades propostas na sala de informática e/ou acompanham as crianças e adolescentes durante o desenvolvimento das atividades. Para os acompanhantes são propostas atividades de familiarização com o computador, uso do e-mail, redes sociais, pagamento e segunda via de contas, como realizar pesquisas, cursos online, aplicativos de escritório, orientações sobre segurança na internet, entre outros. Estas atividades também são propostas para crianças e adolescentes que possuem pouca familiaridade com computadores e recursos digitais.

\section{Análise dos resultados}

A sala de informática da instituição fica localizada na área da brinquedoteca e possui 6 (seis) computadores, com acesso à internet, configurados com o sistema operacional open source Ubuntu. Todos os dias a sala de informática é liberada para uso por 2 horas no turno da manhã e 2 horas no turno da tarde. Geralmente nossas oficinas são realizadas duas vezes na semana.

A brinquedoteca (Figura 1) na qual fica localizada a sala de informática (Figura 2) é um espaço com uma variedade de brinquedos e jogos, bastante colorido, tornando a atividade lúdica benéfica não somente para pacientes, mas também ao profissional, promovendo sentimentos positivos.

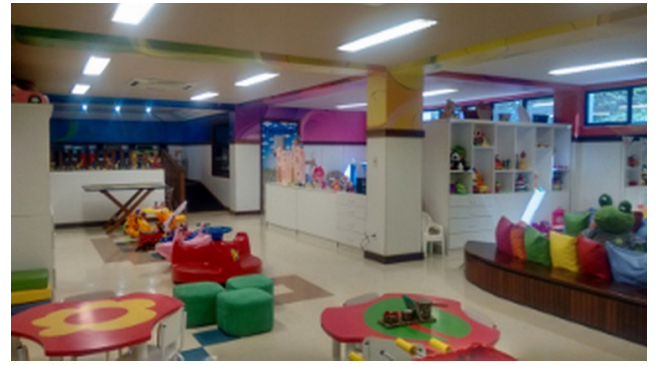

Figura 1. Brinquedoteca

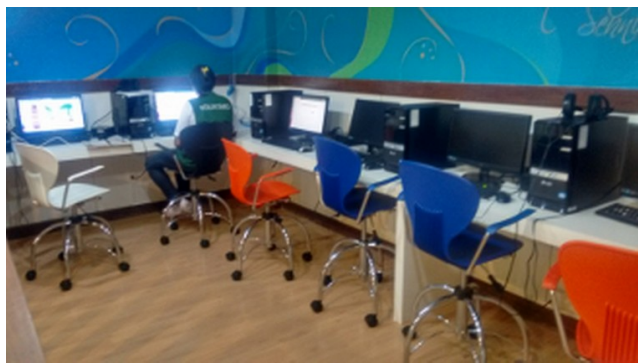

Figura 2. Sala de Informática

Nas oficinas, o nosso objetivo é articular os conteúdos vistos pelos pacientes na classe hospitalar com atividades propostas na sala de informática. Os conteúdos trabalhados na classe hospitalar são planejados para cada semestre. Nossa equipe tem acesso apenas à lista dos conteúdos e temas que serão trabalhados, desprovidos de um cronograma, impedindo que os conteúdos escolares sejam abordados de forma sincronizada com a classe hospitalar e as oficinas de informática.

Dentre os conteúdos trabalhados na classe hospitalar constam datas comemorativas, tais como: Dia da Mulher, Dia do Trabalho, Dia do Índio, Páscoa, Dia do Livro Infantil, Dia das Mães, Dia do Circo, dentre outras. Além destes, os conteúdos 
abordam gêneros textuais, práticas de leitura e escrita, concordância nominal, cores, formas geométricas, noções espaciais, saúde e alimentação, meio ambiente e etc. Além dos jogos online, utilizamos também textos e mensagens educacionais e vídeos que abordam os temas escolares de maneiras simples e divertida.

Dado nosso objetivo de proporcionar uma inclusão social e digital de forma lúdica utilizando o computador como ferramenta para auxiliar o aprendizado, investimos na sedução das crianças e adolescentes pela curiosidade em realizar as atividades propostas. A maioria das crianças e adolescentes já sabe utilizar os recursos básicos do computador e da internet e acessam os sites de jogos onlines que já ficam salvos nos favoritos do navegador. Alguns participantes são tímidos, calados e interagem pouco, mas realizam as atividades que propomos e demonstram gostar por meio de sorrisos ou gestos. Outros já chegam com objetivos bem definidos e nem desejam conhecer a proposta de atividade do dia, apenas solicitando auxílio para acesso a determinados recursos.

Nosso público até o final do ano de 2015 restringia-se a crianças e adolescentes até os dezesseis anos de idade, com os quais, de modo geral, conseguíamos realizar as atividades de cunho educacional propostas. No primeiro semestre do ano de 2016 começaram a aparecer adolescentes maiores de 16 anos na sala de informática. Com estes enfrentamos maior resistência na realização das atividades propostas, em virtude do nosso acervo ser limitado, em se tratando de atividades educacionais atrativas para esta faixa etária. Alguns destes consideram-se avançados e preferem ficar em redes sociais como o Facebook, assistindo vídeos no YouTube ou escolhem jogos de sua preferência, fazendo o uso dos recursos digitais para fins de entretenimento apenas.

Na proposição de novas atividades procuramos identificar com a prática o que as crianças gostam de fazer quando estão na sala de informática e quais os sites que os adolescentes e acompanhantes mais utilizam. Antes de iniciarmos a aplicação de um jogo são explicadas para as crianças e adolescentes como o mesmo funciona: seus objetivos, como movimentar o personagem, mudanças de cenário e regras, além de estabelecer as relações com conteúdos escolares que estão embutidas naquele jogo. Algumas crianças por não saberem manusear o mouse e/ou o teclado, sentem dificuldades e querem sempre um oficineiro por perto. A maioria das crianças capta as informações a respeito das regras do jogo muito rapidamente, outras precisam de mais de uma explicação sobre as regras e, até mesmo, que pelo menos uma fase do jogo seja jogada com a ajuda de um oficineiro.

A apresentação da atividade proposta gera uma destas reações nas crianças e adolescentes: ou se interessam ou não se interessam. Na maioria das vezes percebemos por meio de sorrisos, gestos e expressões que os participantes divertem-se com os jogos propostos. Os jogos com níveis de dificuldade, com bons gráficos e grande disposição de elementos coloridos são os que mais atraem a atenção de crianças e adolescentes.

Observamos que no caso de jogos que possuem pontuação e/ou ranking, as crianças e adolescentes demonstram muita vontade de ganhar o jogo, mudar de fase ou ficar no mínimo em $3^{\circ}$ lugar, colocando-se em competição consigo mesmo e também com os outros participantes. Não se sentem intimidadas com jogos que apresentam vários níveis de dificuldade, pelo contrário, ficam mais estimuladas a descobrir 
maneiras de conseguir vencer o jogo. Em jogos com pontuação/ranking, mesmo quando há competição, esta se dá de forma amistosa, gerando, inclusive, um clima de solidariedade com aqueles que não estão conseguindo realizar a atividade.

Em algumas ocasiões, quando as crianças/adolescentes percebem um outro colega jogando com bastante empolgação e euforia, solicitam aos oficineiros que coloquem o mesmo jogo para mostrar que também são capazes. Às vezes pedem para o colega recomeçar o jogo para ver quem consegue vencer a fase/jogo em menor tempo.

Um aspecto interessante é que jogos em outros idiomas, como inglês, não configuram-se em barreiras ou fator de desestímulo. Inclusive as crianças/adolescentes gostam de jogos que possibilitam o aprendizado de outros idiomas. Quando eles não sabem o que significa alguma palavra, solicitam que os oficineiros façam associação com outros objetos ou outras coisas para que eles tentem advinhar o que é.

Algumas crianças/adolescentes baseados em experiências anteriores já associam que a opção "PLAY" é o botão que deve ser apertado para começar o jogo e que opção "RETRY" é o botão que deve ser apertado quando se deseja reiniciar um jogo ou fase. Estas associações são possibilitadas por meio das affordances convencionais ou metafóricas, características de um objeto capazes de revelar aos seus usuários as operações e manipulações que podem fazer com ele.

A aderência às atividades propostas é maior em crianças e adolescentes do sexo feminino. A Tabela 1 apresenta resumidamente os tipos de jogos online que mais atraem as crianças e adolescentes. Vale salientar que devido a rara aparição de adolescentes do sexo masculino na sala de informática ou a resistência que os mesmos apresentam para realizar as atividades propostas, identificamos poucos tipos de atividades que atraem os mesmos.

Tabela 1. Tipos de jogos onlines que atraem crianças e adolescentes

\begin{tabular}{|c|c|c|}
\hline \multirow{2}{*}{ SUBGRUPOS } & \multicolumn{2}{|c|}{ SEXO } \\
\hline & FEMININO & MASCULINO \\
\hline CRIANÇAS & $\begin{array}{l}\text { Jogos de cuidar (vestir, maquiar, pentear, } \\
\text { alimentar). Jogos de cozinhar. Jogos de } \\
\text { colorir e desenhar. Jogos cognitivos } \\
\text { (raciocínio lógico, memorização, } \\
\text { operações matemáticas) }\end{array}$ & $\begin{array}{l}\text { Jogos de corrida de carro e moto. } \\
\text { Jogos de cozinhar . Jogos de colorir e } \\
\text { desenhar. Jogos cognitivos } \\
\text { (raciocínio lógico, memorização, } \\
\text { operações matemáticas) }\end{array}$ \\
\hline ADOLESCENTES & $\begin{array}{c}\text { Jogos cognitivos (tabuleiro, raciocínio } \\
\text { lógico, memorização, operações } \\
\text { matemáticas). Jogos de colorir e } \\
\text { desenhar }\end{array}$ & $\begin{array}{c}\text { Jogos sociais (permitem interação } \\
\text { com outros participantes). Jogos de } \\
\text { colorir e desenhar }\end{array}$ \\
\hline
\end{tabular}

Um jogo que algumas crianças e adolescentes escolhem quando não desejam realizar as atividades propostas é o Habbig (http://habbig.nl). Trata-se de um jogo social onde você conhece pessoas diferentes, faz amizades, conversa com os amigos, cria jogos, completa missões e tarefas, entre outros. Constitui-se em um jogo que possibilita interagir, competir e ainda fazer amigos de uma maneira diferente. 
V Congresso Brasileiro de Informática na Educação (CBIE 2016)

Anais do XXII Workshop de Informática na Escola (WIE 2016)

Durante a utilização do jogo Gartic (https://gartic.com.br) - jogo de desenhos online cujo objetivo é acertar o que o outro jogador está desenhando - por uma das crianças, um dos jogadores começou a desenhar uma imagem obscena. A criança por iniciativa própria denunciou o usuário online clicando no botão "Denunciar". Provavelmente, esta criança já foi orientada por um adulto em situações similares. Este acontecimento alerta para a necessidade do acompanhamento, principalmente das crianças, durante a utilização da internet para alertá-las sobre os perigos e ensiná-las como agir nestas situações.

A Tabela 2 relaciona alguns sites utilizados para seleção dos jogos online. Cada site possui jogos dos mais variados tipos.

Tabela 2. Relação de sites de jogos online

\begin{tabular}{|c|c|c|}
\hline$\underline{\text { http://www.escolagames.com.br }}$ & $\underline{\text { http://www.jogosdelogica.net }}$ & $\underline{\text { https://rachacuca.com.br }}$ \\
\hline$\underline{\text { http://iguinho.com.br }}$ & $\underline{\text { http://jogos360.uol.com.br }}$ & $\underline{\underline{\text { htp:}: / / w w w . s m a r t k i d s . c o m . b r ~}}$ \\
\hline$\underline{\text { http://www.clickjogos.com.br }}$ & $\underline{\text { http://br.hao123.com/games }}$ & $\underline{\text { http://www.ojogos.com.br }}$ \\
\hline$\underline{\text { http://www.friv.com }}$ & $\underline{\text { http://www.jogospuzzle.com }}$ & $\underline{\text { http://www.vogais.com.br }}$ \\
\hline$\underline{\text { http://www.jogosdaescola.com.br }}$ & $\underline{\text { http://novaescola.org.br/jogos }}$ & $\underline{\text { http://poki.com.br }}$ \\
\hline$\underline{\text { http://gafaa.com }}$ & $\underline{\text { http://jogoseducativos24.com.br }}$ & $\underline{\text { http://www.silabas.com.br }}$ \\
\hline
\end{tabular}

Dentre as crianças e adolescentes existem aquelas que aventuram-se nas atividades propostas no website do projeto Code.org (https://code.org), que tem como objetivo estimular o raciocínio lógico através do ensino da programação; também existem aquelas que já sabem ler e escrever e optam por aprender um novo idioma por meio da plataforma colaborativa gratuita Duolingo (https://pt.duolingo.com).

De 2012 até 2016 foram realizadas 117 oficinas de informática, sendo o ano de 2013 o mais expressivo quantitativamente em relação à quantidade de oficinas e de atendimentos realizados (Figura 3), com uma média de 7 crianças e adolescentes por oficina, ultrapassando a quantidade de computadores disponíveis no laboratório - seis máquinas. Tal situação não foi encarada com desânimo, pelo contrário, ela abriu oportunidade para as crianças/adolescentes interagirem entre si, pelo compartilhamento no uso de uma mesma máquina por duas crianças.

Os acompanhantes, em sua maioria mulheres (mães ou tias), são sempre mais tímidos quando o assunto é tecnologia. Eles demonstram curiosidade em saber como cada coisa funciona, principalmente quando as crianças/adolescentes estão interagindo com as atividades propostas. Por meio de estímulo da equipe de estudantes participantes da ACCS, eles acabam sentando perto das crianças e ajudando-os a resolver as questões levantadas pelos jogos (mudar de fase, retirar um obstáculo do caminho, etc).

Já participaram da ação como oficineiros 33 estudantes de graduação e apenas 1 estudante de pós-graduação, sendo cerca de $60 \%$ mulheres e $40 \%$ homens, com expressiva predominância de estudantes oriundos de cursos da área de Ciências Exatas $(79,4 \%)$, seguido da área de Ciências Humanas $(17,6 \%)$ e Ciências Biológicas (3\%). 


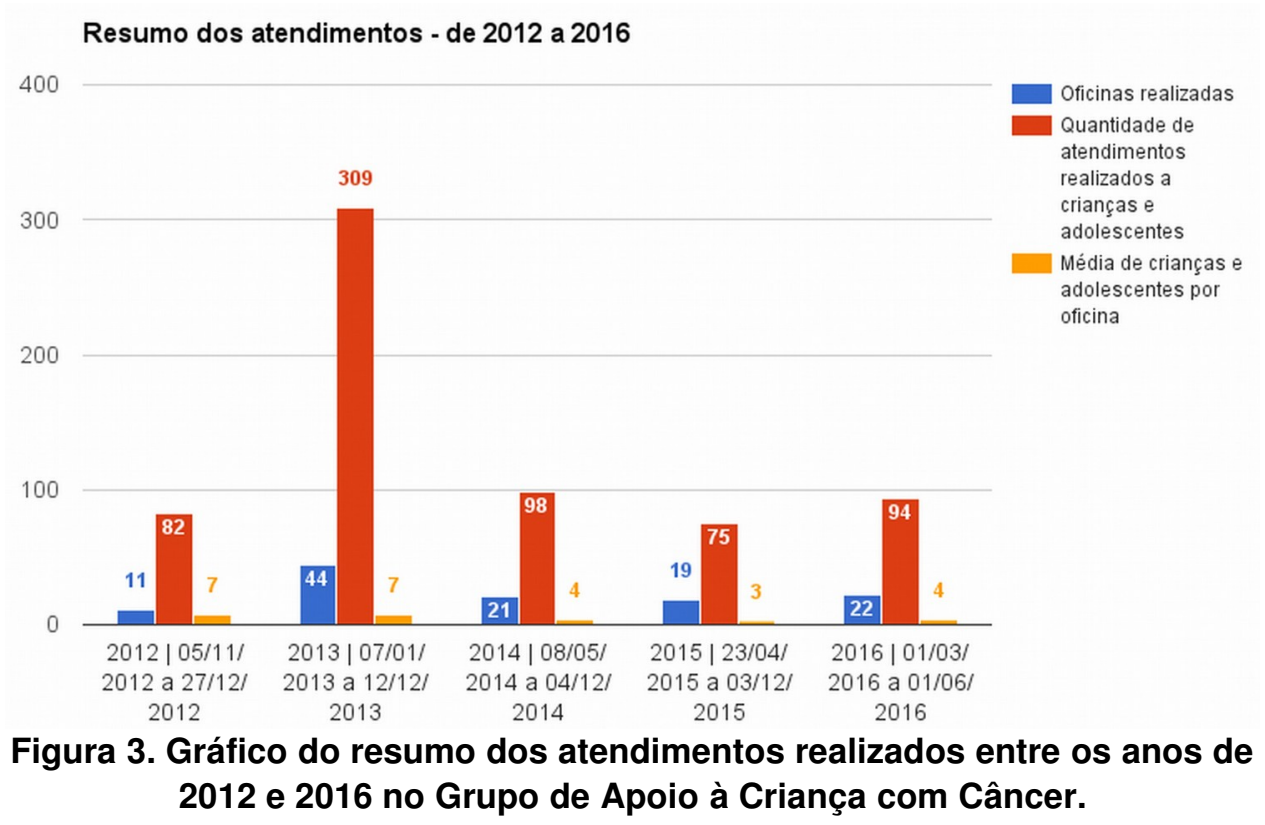

\section{Conclusões}

A eficácia das Tecnologias Digitais de Informação e Comunicação na educação está diretamente ligada ao modo de como estas são aplicadas e adaptadas aos mais diversos contextos existentes, a exemplo do contexto hospitalar abordado nesse artigo. Durante o período que realizamos as atividades no Grupo de Apoio à Criança com Câncer percebemos o grande potencial da utilização de jogos online com fins pedagógicos para o processo educacional desses pacientes, servindo como um instrumento de apoio e reforço dos conteúdos vistos nas aulas realizadas na classe hospitalar.

Tanto as crianças quanto os adolescentes são bastante receptivos à utilização dos jogos como meio principal de ensino de qualquer tema. Portanto exploramos ao máximo o interesse destes pelos recursos lúdicos que os desafiam a novas aprendizagens. Somado a isto, temos o constante desafio de buscar novas atividades para compor nosso acervo, pois as crianças são ávidas por novidades. Além disso, precisamos de atividades que estimulem os adolescentes maiores de dezesseis anos que não consideram as atividades propostas atraentes. Além disso, trabalhando com um público diversificado faz-se também necessário buscar atividades que possam interessar e adequar-se a crianças e jovens autistas, surdos, cegos, entre outros.

Uma das dificuldades que temos é a efetiva integração entre a classe hospitalar e as oficinas, pois só temos acesso à lista de conteúdos abordados em sala, desprovida de cronograma e não temos um feedback da professora da classe hospitalar sobre o desenvolvimento dos alunos após a incorporação das oficinas de informática, muito por conta da alta rotatividade dos pacientes que impede uma análise mais contínua.

Como trabalhos futuros aplicaremos formulários de avaliação (com uma linguagem adequada para cada público), no final de cada oficina, a serem respondidos pelos participantes das atividades realizadas, possibilitando, por meio deste feedback a melhoria das atividades propostas. Dentre os próximos desdobramentos, temos o desenvolvimento de um trabalho de conclusão de curso com o objetivo de modelar um 
V Congresso Brasileiro de Informática na Educação (CBIE 2016)

Anais do XXII Workshop de Informática na Escola (WIE 2016)

sistema tutor inteligente capaz de auxiliar na identificação do progresso das crianças e adolescentes no processo de aprendizagem com jogos online educacionais.

Este trabalho procurou contribuir para o aumento da qualidade do atendimento em serviços de Oncologia Pediátrica, fornecendo dados para subsidiar a organização e adequação do espaço lúdico para promoção de inclusão social e digital de crianças e adolescentes atendidos pelo GACC.

\section{Agradecimentos}

As autoras agradecem o apoio do Grupo de Apoio à Criança com Câncer (GACC Bahia) e os financiamentos obtidos por meio dos editais PROEXT - MEC/SESu 2015 e Edital ACCS da Pró-Reitoria de Extensão da UFBA.

\section{Referências}

ANTUNES, C. Jogos para estimulação das múltiplas inteligências. Petropólis: Vozes, 1999.

BATISTA, C. A. A classe hospitalar no Brasil e o papel do profissional docente. Monografia (Especialização Lato Sensu em Formação de Professores com Ênfase no Magistério Superior) - Instituto Federal de Educação, Ciência e Tecnologia de São Paulo, IFSP, 2014.

BRASIL. Constituição (1988). Constituição da República Federativa do Brasil. Brasília, DF: Senado Federal: Centro Gráfico, 1988. 292 p.

BRASIL. Lei n. 11.104, de 21 de março de 2005. Dispõe sobre a obrigatoriedade de instalação de brinquedotecas nas unidades de saúde que ofereçam atendimento pediátrico em regime de internação. Disponível em: http://www.planalto.gov.br/ccivil_03/_Ato2004-2006/2005/Lei/L11104.htm. Acesso em: 21 fev. 2016.

CARVALHO, A. M.; BEGNIS, J. G. Brincar em unidade de atendimento pediátrico: aplicações e perspectivas. Psicologia em Estudo, Maringá, v. 11, n. 1, p. 109-117, jan./abr. 2006.

LIMA, L. M. et al. Adoecer de câncer: o agir e o sentir do grupo familiar. Ciência, Cuidado e Saúde. 2012;11(1):106-12.

NIGRO, M. Hospitalização: o impacto na criança, no adolescente e no psicólogo hospitalar. São Paulo: Casa do Psicólogo, 2004.

SANTOS, S. M. P. Brinquedoteca: o lúdico em diferentes contextos. Petrópolis-RJ: Vozes, 1997.

SANTOS, D. A.; SANTOS, J. M. O.; GOMES, A. S. M. Uma experiência de inclusão digital para crianças e adolescentes oncológicos. In: Anais do Workshop de Inclusão Digital da ERBASE (WInDBASE 2016). Maceió. v. 1. p. 25-33.

SOARES, M. S.; SANTAROSA, L. M. C. A motivação de crianças hospitalizadas para o uso dos Ambientes Digitais Virtuais. In: XIII Workshop sobre Informática na Escola. Rio de Janeiro, 2007. 